\title{
Desempenho dos enfermeiros na atenção primária perante o paciente com anemia falciforme: uma revisão integrativa
}

\author{
Nurse's performance in primary care before the patient with \\ falciform anemia: an integrative review
}

\author{
Nágela Bezerra Siqueira, Mônica Kallyne Portela Soares
}

Como citar este artigo:

SIQUEIRA, NÁCELA B.; SOARES, MÔNICA KALLYNE P.; Desempenho dos enfermeiros na atenção primária perante o paciente com anemia falciforme: uma revisão integrativa. Revista Saúde (Sta. Maria). 202 1; 47 ( 1 ).

\section{Autor correspondente:}

Nome: Nágela Bezerra Siqueira

Telefone: (88)-994325704

E-mail: nagelasiqeira1997@gmail.

com

Formação Profissional: Discente de Enfermagem pela Faculdade Princesa do Oeste (FPO) que fica na cidade de Crateús, CE, Brasil

Filiação Institucional: Faculdade Princesa do Oeste

Endereço para correspondência:

Rua: Antonio Catunda n: 570

Bairro: São Vicente

Cidade: Crateús

Estado: CE

CEP: 63700-295

Data de Submissão:

$21 / 11 / 2020$

Data de aceite:

02/03/202 I

Conflito de Interesse: Não há conflito de interesse

\section{(cc) $\mathrm{BY}-\mathrm{NC}-\mathrm{ND}$}

\section{RESUMO}

Este estudo tem como objetivo apresentar os resultados da revisão realizada nos bancos de dados, almejando destacar a relevância do profissional de enfermagem nas ações terapêuticas da Anemia Falciforme. Estudo de revisão integrativa, realizado através das bases de dados Scielo, Medline, Lilacs e BDENF, foi coletado estudos correspondentes aos descritores: anemia falciforme e enfermagem, com os achados foram submetidos os seguintes critérios de inclusão: textos completos e disponíveis eletronicamente na íntegra, em idioma português; com recorte temporal de publicação no máximo cinco anos e que abordassem a respeito de pacientes com Anemia Falciforme e respondessem a pergunta norteadora elaborada pela estratégia de PICO. A enfermagem assume um papel de agente político de transformação na sociedade, através de ações que geram um efeito significativo na qualidade de vida dos pacientes com anemia falciforme. Seja no atendimento clínico ou no desenvolvimento de práticas educadoras. A assistência da equipe de enfermagem, voltada ao paciente com anemia falciforme deve ser a de oferecer informações precisas sobre a doença, como também sanar os questionamentos dos familiares. Reconhecendo o outro como sujeito do autocuidado, utilizando escalas de dor, respeitando as particularidades, adotando o lugar do paciente e considerando os fatores culturais, religiosos, psicológicos e sociais nas condutas expressas. Contudo o foco principal da Enfermagem frente a esses pacientes se destaca principalmente nas crises álgicas, onde a prestação de orientações simples e persistentes a respeito dos cuidados com a hidratação e a alimentação, visitas domiciliares, são alternativas de estímulos ao autocuidado. Dessa forma, é importante fornecer aos profissionais de saúde capacitações e materiais atualizados, como protocolos e manuais, o desenvolvimento de programas de educação continuada com enfoque preparatório para que possam atuar oferecendo a melhor assistência.

PALAVRAS-CHAVE: Anemia Falciforme; Atenção Primária; Cuidados de Enfermagem.

\section{ABSTRACT}

This study aims to present the results of the review carried out in the databases, aiming to highlight the relevance of the nursing professional in the therapeutic actions of this anomaly. An integrative review study, carried out in the Scielo, Medline, Lilacs and BDENF databases, collected studies corresponding to the descriptors: sickle cell anemia and nursing, with the following inclusion criteria found: complete texts and available electronically in full, in Portuguese ; with a publication deadline of a maximum of five years and addressing patients with sickle cell disease and answering the guiding question elaborated by the PICO strategy. Nursing assumes a role as a political agent for the transformation of society, through actions that generate significant effects on the quality of life of sickle cell patients. Whether in clinical care or in the development of educational practices. The assistance of the nursing team, aimed at the patient with sickle cell anemia, should be in the sense of providing accurate information about the disease, as well as in clarifying family members' doubts. Recognize the other as a subject of self-care, use pain scales, respect the particularities, adopt the patient's place and consider cultural, religious, psychological and social factors in the expressed behaviors. But the main focus of Nursing with these patients will be the reduction of pain in pain crises. The provision of simple and persistent guidelines regarding care with hydration, with food, with home visits, are alternatives to encourage self-care. Thus, it is important to provide health professionals with up-to-date training and materials, as well as the development of permanent education programs with a preparatory focus so that they can act offering the best assistance. 


\section{INTRODUÇÃO}

A anemia falciforme (AF) é uma doença genética hereditária monogênica incurável e que para se manifestar em um indivíduo, necessita possuir o par de alelos homozigotos para exercer dominância. Essa enfermidade é resultado de uma modificação que gera uma permuta no aminoácido ácido glutâmico, presente na sexta posição da cadeia beta globina, pelo aminoácido valina. Essa modificação ocorre devido a um erro do códon que realiza a codificação do ácido glutâmico, produzindo essa doença multifatorial'1.

A mutação gênica dos alelos causadores da AF se deu na África, há milhares de anos, onde resultou na alteração do gene responsável pela formação da hemoglobina, interferindo no seu desempenho e consequentemente, contribuindo para o surgimento de vários acometimentos clínicos. Dentre os sinais e sintomas, citam-se dores nos ossos e na barriga; infecções; icterícia; úlceras nos membros inferiores; complicações ao longo da vida em órgãos como pulmão, fígado, rins e coração; nos homens pode haver priapismo, um acometimento involuntário que pode gerar constrangimento, dor e levar a amputação $0^{1,2}$.

Os primeiros casos de anemia falciforme foram registrados nos Estados Unidos, por meio de necropsias realizadas em afro-americanos, com antecedentes clínicos que constavam semelhanças com a AF. Esta doença é de prevalência étnica, acometendo afrodescentes e povos miscigenados. A explicação para a entrada e incorporação do gene falciforme no território brasileiro deve-se a imigração compulsória dos nativos africanos para serem escravizados², sendo agregados ao nosso país, de maneira que hoje é considerado miscigenado, não sendo mais possível alegar que a AF acomete apenas pessoas de pele negra.

A porta de entrada para pacientes com AF para a Rede de Saúde Pública é através da Atenção Básica (AB), que tem como responsabilidade a integração desses pacientes ao cuidado primário ofertado. Dentro deste contexto, o profissional de saúde de referência no atendimento e prestação de serviços, cuidados e intervenções na $A B$ é 0 Enfermeiro. A enfermagem assume um papel de agente político de transformação através de ações que geram efeitos significativos na qualidade de vida desses pacientes, seja no atendimento clínico ou no desenvolvimento de práticas educadoras direcionadas ao enfrentamento de cada situação específica, sendo essa uma das principais atuações do enfermeiro na Atenção Primária (AP), de modo a estimular o autocuidado³.

Nesse âmbito, é notória a atuação dos profissionais de saúde, no que se refere a AF e sua relevância, sendo imprescindível a atuação médica. Por muito tempo o desempenho da enfermagem frente a esses pacientes era limitado e insuficiente, tornando o tratamento e acompanhamento mais difícil, mesmo diante de altas taxas de casos prevalentes e incidentes, que indicavam uma forte predominância e instalação desses genes no Brasil, tornando necessário o desenvolvimento de políticas públicas voltadas a entender essa contingência. Portanto, a AF deixou de ser uma especialidade médica e se tornou foco da $\mathrm{AP}^{4}$. 
No contexto epidemiológico, a AF é a doença genética mais comum do Brasil, o que reflete a necessidade de profissionais cada vez mais capacitados para lidar com os pacientes com AF de maneira coerente e com excelência. Dessa forma, a AP deve ser a entrada desses pacientes à Rede de Serviços de Saúde Pública, responsável por prestar um acompanhamento mais próximo. Entretanto, acaba que os serviços não se tornam totalmente eficientes como esperado devido ao baixo nível de domínio dos profissionais que nele atuam ${ }^{5,6}$.

Por isso, pontua-se a importância e primordialidade de uma equipe multiprofissional para o desempenho de diagnósticos, cuidados e orientação para esse paciente. A atuação da enfermagem frente a esta doença é abrangente, englobando desde a realização do exame de rastreio para identificação de doenças congênitas, como a própria AF por meio da Triagem Neonatal (teste do pezinho), orientação e aconselhamento genético (de acordo com a legislação brasileira), intervenções de enfermagem em casos de urgência e emergência, principalmente em situações severas, em que não houve adesão ao tratamento 4 .

Com isso, este estudo tem como objetivo apresentar os resultados da revisão realizada nos bancos de dados, almejando destacar as principais contribuições do profissional de enfermagem nas ações terapêuticas desta anomalia e averiguar o domínio do conhecimento desses profissionais a respeito do tema.

\section{MÉTODO}

Trata-se de um estudo de revisão integrativa, realizado através das bases de dados Scientific Electronic Library Online (Scielo), Medical Literature Analysis and Retrieval System Online (Medline), Literatura Latino-americana e do Caribe em Ciências da Saúde (Lilacs) e Base de Dados da Enfermagem (BDENF), onde foram coletados estudos correspondentes aos descritores "anemia falciforme" AND "enfermagem".

Utilizou-se a estratégia PICO, instrumento este, capaz de auxiliar na construção de questionamentos guias de pesquisas e na busca de evidências. Faz uso dos acrônimos: Paciente, Intervenção, Comparação e "Outcomes" (desfecho) ${ }^{7}$. Na presente pesquisa, têm-se P: anemia falciforme; I: atuação dos enfermeiros; C: sem comparação; O: assistência na atenção primária.

Seguiram-se os seguintes critérios de inclusão: artigos completos e disponíveis eletronicamente na íntegra, em idioma português; com recorte temporal de publicação de cinco anos (2015-2020), abordando a respeito da conduta dos profissionais de enfermagem com pacientes com AF, assim como seu domínio sobre a temática, desde que respondessem a seguinte questão norteadora: Quais as ações e os desafios do Enfermeiro na Atenção Primária perante o paciente com Anemia Falciforme e como proceder? Já como critérios de exclusão, citam-se: teses, dissertações, monografias e repetições encontradas em outros bancos de dados.

As etapas deste estudo foram divididas em dois momentos, onde o primeiro se dividindo em quatro fases: Busca 
nas bases de dados; Seleção sistemática dos artigos, aplicando os critérios de inclusão e exclusão; Leitura dos artigos; Apresentação dos estudos.

\section{DISCUSSÃO}

O resultado da seleção obtida do primeiro momento está expresso no quadro 1, onde se obteve um total de seis artigos, sendo encontrados nas bases de dados Scielo e BDENF. Não foram encontrados artigos que respeitassem os critérios estabelecidos nas bases de dados Lilacs e Medline. O quadro foi organizado de acordo com o título, objetivos, ano de publicação e base de dados encontrado. A leitura foi realizada na ordem de seleção dos artigos, onde estes foram numerados para fins organizacionais.

Quadro 1. Informações dos artigos selecionados.

\begin{tabular}{|c|c|c|c|}
\hline Artigo & Objetivos & Ano de \\
publicação & Base de Dados \\
\hline $\begin{array}{c}\text { 1.Assistência de Enfermagem na } \\
\text { Doença Falciforme na Estratégia } \\
\text { Saúde da Família }\end{array}$ & $\begin{array}{c}\text { Avaliar os cuidados realizados por } \\
\text { enfermeiros as pessoas vivendo com } \\
\text { Anemia Falciforme }\end{array}$ & 2018 & BDENF \\
\hline $\begin{array}{c}\text { 2.Avaliação e Intervenção na Família } \\
\text { de Adolescentes com Doença } \\
\text { Falciforme }\end{array}$ & $\begin{array}{c}\text { Avaliar a estrutura/ funcionalidade/ } \\
\text { desenvolvimento da família de adolescentes } \\
\text { com doença falciforme e implementar } \\
\text { intervenções após evidências identificadas. }\end{array}$ & 2017 & BDENF \\
\hline $\begin{array}{c}\text { 3.O Cuidar do Enfermeiro ao } \\
\text { O objetivo deste estudo é descrever o } \\
\text { cuidado do enfermeiro ao paciente com } \\
\text { anemia falciforme. }\end{array}$ & 2015 & Scielo \\
\hline $\begin{array}{c}\text { 4.Anemia falciforme: cuidados } \\
\text { realizados por enfermeiros na } \\
\text { Estratégia Saúde da Família }\end{array}$ & $\begin{array}{c}\text { Avaliar os cuidados de enfermagem a nível } \\
\text { de Estratégia de Saúde da Família } \\
\text { realizados por enfermeiros a } \\
\text { pessoas vivendo com Anemia Falciforme. }\end{array}$ & 2015 & Scielo \\
\hline $\begin{array}{c}\text { 5.Anemia falciforme: conhecimento } \\
\text { do enfermeiro sobre o }\end{array}$ & $\begin{array}{c}\text { Analisar o conhecimento do enfermeiro } \\
\text { sobre o desenvolvimento da anemia } \\
\text { falciforme em uma Unidade de Saúde } \\
\text { Assistencialista da Atenção Secundária da } \\
\text { rede privada em Fortaleza-CE. }\end{array}$ & 2017 & Scielo \\
\hline $\begin{array}{c}\text { Integrativa } \\
\text { em Enfentimento da doença }\end{array}$ & $\begin{array}{c}\text { Trata-se de uma revisão integrativa que } \\
\text { objetivou identificar como os profissionais de } \\
\text { enfermagem vêm abordando a pessoa com } \\
\text { doença falciforme }\end{array}$ & 2015 & Scielo \\
\hline
\end{tabular}

Fonte: Própria.

No segundo momento, foi respondida a pergunta norteadora e o quadro 2 apresenta a aplicação da estratégia de 
PICO nos estudos selecionados até a formação da questão guia deste estudo. Esse método consiste em identificar os acrônimos para cada artigo selecionado: "Quem/qual é o problema/paciente do artigo?"; "Qual a intervenção utilizada?";

"Qual procedimento padrão de comparação?"; "Qual o desfecho esperado?".

Quadro 2. Aplicação da estratégia PICO nos resultados encontrados.

\begin{tabular}{|c|c|c|c|c|}
\hline Artigo & Problema/Paciente & Intervenção & $\begin{array}{c}\text { Controlel } \\
\text { Comparação }\end{array}$ & $\begin{array}{l}\text { Outcomes } \\
\text { (Desfecho) }\end{array}$ \\
\hline 1 & $\begin{array}{l}\text { Carência dos profissionais na } \\
\text { prática desenvolvida e no } \\
\text { conhecimento do cuidado. }\end{array}$ & $\begin{array}{c}\text { Atua como gatilho de } \\
\text { discussões sobre a temática, além } \\
\text { de oferecer embasamentos teóricos } \\
\text { e práticos para os profissionais. }\end{array}$ & - & - \\
\hline 2 & $\begin{array}{l}\text { Reconhecer no contexto familiar } \\
\text { as dificuldades de aspectos } \\
\text { sociais e religiosos, como as } \\
\text { expressadas pelo paciente. } \\
\text { Assegurar um atendimento } \\
\text { holístico,relacionando fatores } \\
\text { biológicos, sociais e espirituais. }\end{array}$ & $\begin{array}{c}\text { Incrementação da família quanto } \\
\text { aos seus aspectos cognitivos, } \\
\text { afetivos e culturais, auxiliando novas } \\
\text { soluções. }\end{array}$ & - & - \\
\hline 3 & $\begin{array}{l}\text { Como o profissional de } \\
\text { Enfermagem pode auxiliar no } \\
\text { cuidado ao paciente alvo nas } \\
\text { dificuldades diárias. }\end{array}$ & $\begin{array}{l}\text { Prevenir complicações, uso da SAE, } \\
\text { ações educativas, alívio da dor: } \\
\text { medicamentos ou outras } \\
\text { alternativas, reconhecer fatores } \\
\text { desencadeantes de situações } \\
\text { agudas e crônicas. }\end{array}$ & - & - \\
\hline 4 & $\begin{array}{c}\text { Carências na prática desenvolvida } \\
\text { e no conhecimento dos cuidados } \\
\text { relacionados aos pacientes. }\end{array}$ & $\begin{array}{c}\text { Detecta a } \\
\text { necessidade da implantação de uma } \\
\text { política pública, objetivando a } \\
\text { prestação de uma assistência de } \\
\text { qualidade aos } \\
\text { indivíduos com AF. }\end{array}$ & - & - \\
\hline 5 & $\begin{array}{c}\text { Analisa o conhecimento do } \\
\text { enfermeiro acerca da AF em uma } \\
\text { Unidade Assistencialista da } \\
\text { Atenção Secundária da Rede } \\
\text { Privada. }\end{array}$ & $\begin{array}{l}\text { Orientar e promover autonomia ao } \\
\text { paciente alvo, capacitando-o a } \\
\text { reconhecer sinais e sintomas, } \\
\text { prevenir crises e realizar } \\
\text { acompanhamento individualizado. }\end{array}$ & - & - \\
\hline 6 & $\begin{array}{l}\text { Como a enfermagem tem } \\
\text { abordado estudos publicados a } \\
\text { respeito de pessoas com AF. }\end{array}$ & $\begin{array}{c}\text { Aponta perspectivas de } \\
\text { investigações que ampliem os } \\
\text { conhecimentos e debates na área } \\
\text { de conhecimento da enfermagem do } \\
\text { paciente alvo, visando uma } \\
\text { assistência eficaz para melhoria da } \\
\text { qualidade de vida. }\end{array}$ & - & - \\
\hline
\end{tabular}

Fonte: Própria. 
A pesquisa permitiu comprovar a existência da deficiência a respeito do nível de conhecimento dos profissionais de enfermagem em relação às medidas de cuidados e seguimento do paciente com AF, mostrando pouco conhecimento sobre esse agravo, além de dúvidas por parte dos profissionais acerca do desenvolvimento da doença e de suas complicações. 0 artigo 1 corrobora essa afirmação ao indicar a necessidade da realização de educação permanente e capacitação para os profissionais, devido a insuficiência sobre o tema.

Os estudos afirmam que a pessoa com AF necessita de cuidados por toda sua vida, desta forma, há necessidade de um acompanhamento mais próximo, sendo colocado a AP como porta de entrada à Rede de Saúde e o serviço que este paciente mais buscará. Por sua vez, o artigo 4 demonstra a carência mais intimamente relacionada aos procedimentos de enfermagem, onde as práticas desenvolvidas pelos enfermeiros da AP poderiam ser mais singulares, variando de acordo com a necessidade do paciente. Pessoas com anemia falciforme são dependentes de cuidados específicos que podem, em muitos casos, ser realizados por eles mesmos, com a ajuda e encorajamento de pessoas próximas, como ações de educação em saúde e acompanhamento.

Porém, com o agravamento dos sinais e sintomas da doença, esses indivíduos acabam procurando auxílio específico nos serviços de Saúde de Urgência. Contudo, como cada indivíduo reage de maneira específica ao acometimento clínico da AF, existem aqueles que, mesmo com os devidos cuidados, ainda apresentam crises agudas constantes com dores intensas nos ossos, na barriga e em outras partes do corpo, assim como também infecções corriqueiras. Todos esses fatores podem ser sanados por meio da promoção ao autocuidado e estímulo à autonomia, onde torna-se fundamental o núcleo familiar. O paciente com AF precisa ter conhecimento de sua condição, mas a família também precisa compreender tanto quanto, como é apontado no estudo 5. Em tese, a devida orientação e acompanhamento devem ocorrem a partir da identificação da doença congênita, por meio da Triagem Neonatal. A atuação da enfermagem deve ser constante no que diz respeito aos primeiros cuidados do neonato com AF, focando no bem estar do paciente, atentando quanto ao nível de hidratação e demonstrações de dor ${ }^{6}$.

E como a AF não tem cura e é crônica, o principal fator vai ser o diagnóstico precoce e o acompanhamento do paciente desde o seu nascimento até sua fase adulta, levando em consideração as particularidades de cada indivíduo, assumindo como meta seu favorecimento para que esse paciente tenha uma vida de qualidade. Para isso, a assistência da equipe de Enfermagem deve ser voltada a esse paciente com intuito de oferecer informações precisas sobre a doença, como também sanar os questionamentos dos familiares. Reconhecer e capacitar o outro como sujeito do próprio cuidado, atuar com respeito às particularidades, com empatia e considerar os fatores culturais, religiosos, psicológicos e sociais nas condutas expressas. Todas as atuações do enfermeiro nas ações práticas educativas influenciam no convívio do indivíduo com o meio social, propiciando as condutas serem menos traumáticas e com isso, auxiliar na obtenção de um prognóstico mais eficiente 8,9 . 
Por isso a importância dos Enfermeiros atuarem nos Serviços de Saúde, especialmente na Atenção Básica, e estarem preparados e capacitados para atender a essa demanda da maneira mais adequada possível, tornando ímpar o trabalho da equipe no acompanhamento dessas pessoas, com uso de alternativas não farmacológicas, como é expresso no artigo 6. Existem ainda alternativas não-invasivas e não-farmacológicas capazes de propiciar alívio, amenizar a ansiedade e a fadiga, como a musicoterapia, que tem mostrado grande satisfação no ambiente familiar dos pacientes falciformes ${ }^{8}$.

Nesse contexto, as complicações da AF geralmente não são resolvidas na AB, mas sua suspeita e diagnóstico podem sim ocorrer em um acompanhamento de rotina, dessa forma, em mediante caso de urgência, as intervenções de Enfermagem devem ser voltadas a amenizar tal ocorrência. Todavia, nos estudos 1, 2, 5 é perceptível a pouca participação e envolvimento do Enfermeiro no acompanhamento domiciliar e no seio familiar, logo não tem como saber como funciona a rotina desse indivíduo e se os cuidados são postos em prática. Pessoas com AF que não realizam o acompanhamento regular de sua doença, estão sujeitas a variadas crises, como anemia (que acarreta hipodesenvolvimento, maturação sexual comprometida, insuficiência cardíaca, cálculo biliar, fadiga, podendo se estabelecer hipossaturação), dor (artralgia, dor abdominal, síndrome mão-pé), lesão de órgãos (infecções, insuficiência funcional, asplenia, síndrome torácica aguda, hipertensão pulmonar, acidente vascular cerebral, insuficiência renal) e úlcera de perna ${ }^{1,13}$.

Então o principal foco da Enfermagem perante esses pacientes visa, desde a consulta naAP, englobar orientações, sanar dúvidas, como a realização de procedimentos e intervenções mais complexos, com foco na diminuição das crises álgicas, sendo necessário um acompanhamento clínico rigoroso a esses pacientes, sempre registrando os variados fenômenos encontrados; a atenção a cuidados básicos que não podem ser cessados, como a prestação de orientações simples e persistentes a respeito dos cuidados com a hidratação (que deve ser constante), alimentação (baseada na necessidade do paciente e regrada) e com visitas domiciliares, podem atuar como alternativas de estímulos ao autocuidado, elevando a autonomia do paciente em poder se responsabilizar pela conquista de sua saúde. Responsabilidade essa, que quando não alcançada, torna-se necessário a busca ao paciente, sendo a chave para o sucesso do tratamento, a persistência, tanto por parte do paciente, como do profissional ${ }^{9,14}$.

\section{CONSIDERAÇÕES FINAIS}

Em suma, é possível concluir que a AF, por ser uma doença incurável e por apresentar muitos casos clínicos, necessita de uma equipe de saúde multiprofissional, para isso é esperado que todos os componentes da equipe sejam capazes de identificar, tratar, intervir e realizar o acompanhamento necessário que os pacientes com anemia falciforme precisam, especialmente os que atuam diretamente no fornecimento de cuidados. 
Assim, a enfermagem deve realizar os cuidados e orientações a esse paciente, como também prestar o acompanhamento necessário, sanar dúvidas, realizar orientações, intervenções. Contudo, para um atendimento e assistência de qualidade é inerente e indispensável aos profissionais de saúde a realização de capacitações, recebimento de material atualizado, como manuais e protocolos; e desenvolvimento de programas de educação continuada com enfoque preparatório para que possam atuar oferecendo a melhor assistência.

É sabido da importância que desempenha o enfermeiro na Atenção Primária e Redes de Saúde, exercendo funções em todas as esferas que lhe competem, a fim de garantir o autocuidado, melhora e qualidade de vida dessas pessoas.

\section{REFERÊNCIAS}

1. Brasil. Ministério da Saúde. Secretaria de Atenção à Saúde. Departamento de Atenção Especializada. Doença falciforme: condutas básicas para tratamento / Ministério da Saúde, Secretaria de Atenção à Saúde, Departamento de Atenção Especializada. Brasília : Ministério da Saúde, 2012. 64 p.: il. - (Série B. Textos Básicos de Saúde) ISBN 978-85-334-1932-2

2. Cavalcanti JM, Maio MC. Entre negros e miscigenados: a anemia e o traço falciforme no Brasil nas décadas de 1930 e 1940. História, Ciências, Saúde - Manguinhos, Rio de Janeiro, v.18, n.2, 2011, p.377-406, abr.-jun.

3. Loiola KJ, Fontanezi CTB, Pequeno AMC, et al. Anemia falciforme: conhecimento do enfermeiro sobre o desenvolvimento da doença. Cadernos ESP, Ceará 2017, 11(1): 18-28;

4. Gomes LM. Acesso e assistência à pessoa com anemia falciforme na Atenção Primária. Acta Paul Enferm. $2014 ; 27(4): 348-55$

5. Sírio Libanês. Doença Falciforme é um dos distúrbios genéticos mais comuns no Brasil [publicação na web]. 2017. [Acesso em: 21/09/2020]. Disponível em: https://www.hospitalsiriolibanes.org.br/sua-saude/Paginas/doenca-falciforme-disturbios-geneticos-comuns-brasil.aspx\#: :text=Segundo\%20estimativas\%20do\%20Minist\%C3\%A9rio\%20 da,heredit $\%$ C3\%A1rios $\% 20$ mais $\% 20$ comuns $\% 20$ no $\% 20 \mathrm{~Pa} \%$ C3\%ADs.

6. Souza São Bento PA; Castro TA; Silva CTC; Rodrigues LP; et al Diagnósticos e Cuidados de Enfermagem para a Pessoa Hospitalizada com Doenças Falciformes: Um Estudo Pautado em NANDA (2009-2011). Revista de 
Pesquisa Cuidado é Fundamental Online [Internet]. 2011;3(4):2579-2592.

7. Santos MARC, Galvão MGA. A elaboração da pergunta adequada de pesquisa. Resid Pediatr. 2014;4(2):53-56

8. Almeida MM, Santos MS, Silva FWT. Assistência de enfermagem na Doença Falciforme na Estratégia Saúde da Família. Rev Fund Care Online. 2018 jan./mar.; 10(1):36-45.

9. Galdino ELV, Barcellos JFM, Silva KMM. O Cuidado do Enfermeiro ao Paciente com Anemia Falciforme. Revista Científica da FASETE, Rio de Janeiro, 2017, (3): 185-296;

10. Felix AA, Souza HM, Ribeiro SBF. Aspectos epidemiológicos e sociais da doença falciforme. Rev. Bras. Hematol. Hemoter. [Internet]. 2010 [cited 2020 Nov 21] ; 32( 3 ): 203-208

11. Almeida MM, Santos MS, Silva FWT. Assistência de enfermagem na Doença Falciforme na Estratégia Saúde da Família. Rev Fund Care Online. 2018 jan./mar.; 10(1):36-45.

12. Silva FWT, Paiva ECC, Santos MS, et al. Anemia falciforme: cuidados realizados por enfermeiros na Estratégia Saúde da Família. Rev. Pre. Infec e Saúde. 2015;1(4):18-26.

13. Oliveira PP de, Santos KL, Silva FL et al. Avaliação e Intervenção na Família de Adolescentes com Doença Falciforme. Rev enferm UFPE on line., Recife, 2017, 11(4):1552-64;

14. Carvalho EMMS, Santos FHES, Anjos CD. Doença falciforme nas pesquisas em enfermagem: uma revisão integrativa. Rev Baiana Enferm[Internet]. 2015 